\title{
Health disparities between lesbian, gay, and bisexual adults and the general population in South Korea: Rainbow Connection Project I
}

\author{
Horim Yi' ${ }^{1}$, Hyemin Lee', Jooyoung Park' ${ }^{1}$ Bokyoung Choi', Seung-Sup Kim ${ }^{1,2}$ \\ 'Department of Public Health Sciences, Graduate School of Korea University, Seoul, Korea; '2Department of Social and Behavioral Sciences, \\ Harvard T. H. Chan School of Public Health, Boston, MA, USA
}

\begin{abstract}
OBJECTIVES: This study aims to investigate health disparities between lesbian, gay, and bisexual (LGB) adults and the general population in Korea, where there is low public acceptance of sexual minorities and a lack of research on the health of sexual minorities.

METHODS: The research team conducted a nationwide survey of 2,335 Korean LGB adults in 2016. Using the dataset, we estimated the age-standardized prevalence ratios (SPRs) for poor self-rated health, musculoskeletal pain, depressive symptoms, suicidal behaviors, smoking, and hazardous drinking. We then compared the SPRs of the LGB adults and the general population which participated in three different nationally representative surveys in Korea. SPRs were estimated for each of the four groups (i.e., gay men, bisexual men, lesbians, and bisexual women).

RESULTS: Korean LGB adults exhibited a statistically significantly higher prevalence of depressive symptoms, suicidal ideation and attempts, and musculoskeletal pain than the general population. Lesbian and bisexual women had a higher risk of poor selfrated health and smoking than the general women population, whereas gay and bisexual men showed no differences with the general men population. Higher prevalence of hazardous drinking was observed among lesbians, gay men, and bisexual women compared to the general population, but was not observed in bisexual men.
\end{abstract}

CONCLUSIONS: The findings suggest that LGB adults have poorer health conditions compared to the general population in Korea. These results suggest that interventions are needed to address the health disparities of Korean LGB adults.

KEY WORDS: Sexual minorities, Health status disparities, Minority health, Republic of Korea

\section{INTRODUCTION}

Previous literatures have well-documented the health disparities experienced by the sexual minorities. These studies have re-

\section{Correspondence: Seung-Sup Kim}

Department of Public Health Sciences, Graduate School of Korea University, 145 Anam-ro, Seongbuk-gu, Seoul 02841, Korea E-mail: ssk3@korea.ac.kr

Received: Jul 5, 2017 / Accepted: Oct 19, 2017 / Published: Oct 19, 2017

This article is available from: http://e-epih.org/

(C) This is an open-access article distributed under the terms of the Creative Commons Attribution License (http://creativecommons.org/licenses/by/4.0/), which permits unrestricted use, distribution, and reproduction in any medium, provided the original work is properly cited.

(C) 2017, Korean Society of Epidemiology ported that compared to the general population, lesbian, gay, and bisexual (LGB) individuals are having more adverse health conditions [1-11]. LGB people have poorer mental health statuses [3-5, $10,11]$, with more prevalent suicidal ideation [6]. Similarly, the prevalence of several chronic diseases [3], including insomnia and dermatitis [1], is higher in the LGB population than in the general population. Furthermore, higher prevalence of risky health behavior is observed among LGB adults, such as heavy drinking [8,9] or smoking $[2,8,9]$.

Despite such findings, studies on the health of LGB people are lacking in South Korea (hereafter Korea). According to a systematic review by Lee et al. [12], there are only 123 published studies that have investigated the health of sexual minorities in Korea as of 2013. Among them, 101 articles (78.9\%) were clinical investigations, mostly case reports of sex reassignment surgeries of transgen- 
der and intersex individuals by healthcare institutions. Only 30 out of the 123 studies have examined the health status of LGB individuals, with even a fewer number of studies $(n=25)$ analyzing the health disparities and the social factors that may be associated with their health.

Due to the paucity of existing studies in the field, previous literatures regarding health disparities of LGB population in Korea have the following limitations. First, most studies were on the health disparities of LGB adolescents, using the Korea Youth Risk Behavior Web-based Survey which is the only nationally representative data that includes sexual orientation in the questionnaire [13-15]. On the other hand, because of the absence of sexual orientation measure in national health surveys targeting adults, there are only few studies on health disparities of adult sexual minorities. Second, no previous research has compared the health status of lesbian and bisexual individuals with the general population. There were few studies examining health disparities of gay men or men who have sex with men (MSM) [16-19], but there was no study on the health disparities of lesbian and bisexual women. Also, studies on MSM have not distinguished between homosexual and bisexual men [16]. Third, studies compared the health status of gay men and MSM with heterosexual adult men sampled these populations separately for their analysis [16-19] and sample size of those studies was relatively small with the largest such study only having 129 MSM participants. Lastly, the health outcomes investigated in the existing studies are limited to only some mental health conditions and health behaviors. Despite previous studies reporting that the Korean LGB population has a higher prevalence of risky health behaviors [14], and have higher prevalence of depressive symptoms $[14,17,20]$ and suicide risk $[15,17]$, none of these studies have studied physical health.

To fill these gaps in knowledge, this study aimed to explore the health disparities between LGB adults and the general population in Korea. The purpose of this study was to compare the health status of LGB individuals and the general population in diverse aspects, including self-rated health, mental health (depressive symptoms, suicidal ideation, suicide attempts), physical health (musculoskeletal pains), and health-related behaviors (smoking and hazardous drinking).

\section{MATERIALS AND METHODS}

\section{Study population}

The data were collected as part of "Rainbow Connection Project I - Korean Lesbian, Gay, \& Bisexual Adults' Health Study.” Participants were eligible if they were aged 19 years or older, living in Korea, and self-identified as LGB.

The survey was administered online for four weeks, from November 11 to December 5, 2016. Participants were recruited by posting ads on two websites frequented by Korean sexual minorities and through the social network services (Facebook and Twitter). This study protocol was approved by the institutional review board (IRB) of Korea University (IRB no. 1040548-KU-IRB-16-
191-A-1), and informed consent for participation and academic use of data were collected from all participants. All participants were rewarded 5,000 Korean won as compensation for participation.

A total of 2,430 people responded to the survey, and we excluded 17 people who did not consent to study participation or academic use of data and 72 people for not providing socio-demographic information. Further, to prevent bias caused by a heterogeneity of age distribution between the LGB and general population, five men in the 61-69 years age range and one woman in the 51-69 years age range were excluded, resulting in a total of 2,335 participants included in the final analysis.

\section{Measurements}

The survey comprised of 173 items in four categories: socio-demographic, sexual orientation, social experience, and health status.

Self-rated health was rated on a 5-point scale as "very good," "good," "fair," "poor," and "very poor." Responses indicating "poor" and "very poor" were classified into the poor self-rated health group. For physical health status, nine physical symptoms were investigated, and musculoskeletal pains were included in this study. The respondents answered "yes" or "no" to three items about having a) back pain, b) muscle pain in the upper limbs, and c) muscle pain in the lower limbs over the past 12 months. Results on six other physical symptoms are shown in Appendix 1.

Although depressive symptoms were measured using the Center for Epidemiologic Studies-Depression Scale-D (CES-D) 20 in the survey, the CES-D 11 was used because the Korea Welfare Panel Study (KWPS), which is a dataset used for the comparison, measured depressive symptoms with CES-D 11. Each item on the CES-D 11 is rated on a 4-point scale (0-3 points), with a maximum score of 33 points. The total score was calculated to a maximum score of 60 points by multiplying 20/11, and a final score of 16 or greater was classified as having depressive symptoms. Suicidal ideation was measured by the question "Have you ever had a serious thought about dying by suicide over the past 12 months?" and suicide attempts were measured by the question "Have you ever attempted to die by suicide over the past 12 months?".

Smoking was measured by asking about pack-year and current smoking status. People who responded to have smoked "more than five packs (100 cigarettes) during their lifetime" and to smoke currently were classified as smokers. Hazardous drinking was measured based on the drinking frequency and volume. Following the Korean national guideline of the hazardous drinking [21], people who drink more than 7 drinks (for men) and 5 drinks (for women) per occasion and more than two time per week were classified as hazardous drinkers.

\section{Statistical analysis}

This study assessed the health status of the Korean LGB adults and compared them with those of the general population. To assess prevalence of health outcomes among the general population in Korea, we analyzed several nationally representative surveys with the closet study period. Those surveys had the same meas- 
ures to assess health outcomes which were used in the survey of Rainbow Connection Project I. More specifically, the Korea National Health and Nutrition Examination Survey VI (KNHANES VI) was used for self-rated health, suicidal ideation and suicide attempts over the past 12 months, and the 4th Korean Working Condition Survey (4th KWCS) was used for musculoskeletal pains. The 10th KWPS was used for depressive symptoms, and the 3rd KWCS was used for smoking and hazardous drinking.

To compare the health status of LGB adults and the general population, indirect standardization was performed, considering heterogeneity of age distribution between the general population in the nationally representative surveys and the LGB adults in the survey of Rainbow Connection Project I. For each health conditions, we calculated standardized prevalence ratio (SPR) as the ratio of the observed number of cases among LGB adults compared with the expected number of cases based on age-specific prevalence derived from the general population participated in nationally representative surveys, and their 95\% confidence intervals (CIs). Men aged 61 or higher and women aged 51 or higher were excluded in the data analysis because there was a small number of LGB participants above those ages. To ensure representativeness of the population, age-specific prevalence of the general population was calculated by weighting each data with cross-sectional individual weights using commands svyset and svy on Stata. SPRs were estimated for each of the four sexual identity groups separately (i.e., gay, bisexual men, lesbian, bisexual women). SPRs for gay and bisexual men and SPRs for lesbians and bisexual women were calculated with men and women in the general population, respectively. All statistical analyses were performed using the Stata/SE version 13.0 (StataCorp., College Station, TX, USA).

Table 1. Socio-demographic characteristics of participants by gender and sexual orientation $(\mathrm{N}=2,335)$

\begin{tabular}{|c|c|c|c|c|c|}
\hline & \multirow{2}{*}{ Total } & \multicolumn{2}{|c|}{ Men (19-60 yr) } & \multicolumn{2}{|c|}{ Women (19-50 yr) } \\
\hline & & Gay & Bisexual & Lesbian & Bisexual \\
\hline \multicolumn{6}{|l|}{ Age $(y r)^{1}$} \\
\hline $19-24$ & $1,074(46.1)$ & $266(29.1)$ & $55(45.1)$ & $299(48.3)$ & $454(66.7)$ \\
\hline $25-29$ & $598(25.6)$ & $250(27.4)$ & $25(20.5)$ & $184(29.7)$ & $139(20.4)$ \\
\hline $30-39$ & $450(19.3)$ & $237(26.0)$ & $26(21.3)$ & $110(17.8)$ & $77(11.3)$ \\
\hline $40-60$ & $213(9.1)$ & $160(17.5)$ & $16(13.1)$ & $26(4.2)$ & $11(1.6)$ \\
\hline \multicolumn{6}{|l|}{ Education } \\
\hline High school or less & $199(8.5)$ & $77(8.4)$ & $12(9.8)$ & $56(9.1)$ & $54(7.9)$ \\
\hline College & $282(12.1)$ & 105 (11.5) & $10(8.2)$ & $87(14.1)$ & $80(11.8)$ \\
\hline University & $1,591(68.1)$ & $594(65.1)$ & $89(73.0)$ & $416(67.2)$ & $492(72.3)$ \\
\hline Graduate school or higher & $263(11.3)$ & $137(15.0)$ & $11(9.0)$ & $60(9.7)$ & $55(8.1)$ \\
\hline \multicolumn{6}{|c|}{ Household income $(10,000 \text { Korean won })^{2}$} \\
\hline$<1,000$ & $397(17.1)$ & $131(14.4)$ & $24(19.7)$ & $107(17.4)$ & $135(20.0)$ \\
\hline $1,000-1,999$ & $364(15.7)$ & $136(15.0)$ & $21(17.2)$ & $94(15.3)$ & $113(16.8)$ \\
\hline $2,000-2,999$ & $430(18.5)$ & $180(19.8)$ & $18(14.8)$ & $104(16.9)$ & $128(19.0)$ \\
\hline $3,000-3,999$ & $366(15.8)$ & $147(16.2)$ & $17(13.9)$ & $96(15.6)$ & $106(15.7)$ \\
\hline $4,000-4,999$ & $248(10.7)$ & $96(10.6)$ & $18(14.8)$ & $68(11.1)$ & $66(9.8)$ \\
\hline$\geq 5,000$ & $516(22.2)$ & $220(24.2)$ & $24(19.7)$ & $146(23.7)$ & $126(18.7)$ \\
\hline \multicolumn{6}{|l|}{ Employment status ${ }^{2}$} \\
\hline Permanent employee & $590(25.4)$ & $299(32.9)$ & $31(25.6)$ & $145(23.6)$ & $115(17.0)$ \\
\hline Precarious employee & $566(24.4)$ & $223(24.6)$ & $22(18.2)$ & $135(22.0)$ & $186(27.4)$ \\
\hline Employer & $106(4.6)$ & $64(7.1)$ & $6(5.0)$ & $26(4.2)$ & $10(1.5)$ \\
\hline Unpaid family worker & $24(1.0)$ & $11(1.2)$ & $2(1.7)$ & $6(1.0)$ & $5(0.7)$ \\
\hline Unemployed & $259(11.2)$ & $96(10.6)$ & $13(10.7)$ & $75(12.2)$ & $75(11.1)$ \\
\hline College or university student & $777(33.5)$ & $215(23.7)$ & $47(38.8)$ & $228(37.1)$ & $287(42.3)$ \\
\hline \multicolumn{6}{|l|}{ Residential area ${ }^{2}$} \\
\hline Seoul Metropolitan City & $1,113(47.8)$ & $482(52.9)$ & $53(43.4)$ & $271(43.8)$ & $307(45.4)$ \\
\hline Other metropolitan cities ${ }^{3}$ & $453(19.5)$ & $165(18.1)$ & $23(18.9)$ & $122(19.7)$ & $143(21.2)$ \\
\hline Other cities and counties & $762(32.7)$ & $264(29.0)$ & $46(37.7)$ & $226(36.5)$ & $226(33.4)$ \\
\hline Total & 2,335 (100.0) & $913(39.1)$ & $122(5.2)$ & $619(26.5)$ & $681(29.2)$ \\
\hline
\end{tabular}

Values are presented as number (\%).

${ }^{1}$ Men:19-60 yr, women: 19-50 yr.

${ }^{2}$ Non-response: household income $(n=14)$, employment status $(n=13)$, and residential area $(n=7)$.

${ }^{3}$ Including Sejong Metropolitan Autonomous City. 


\section{RESULTS}

\section{Socio-demographic characteristics}

The participants' demographic characteristics are shown in Table 1 . Among total participants, $39.1 \%(n=913)$ were gay men, $5.2 \%(n=122)$ were bisexual men, $26.5 \%(n=619)$ were lesbians, and $29.2 \%(n=681)$ were bisexual women, showing a relatively low participation from bisexual men compared to the other three groups. A total of $90.9 \%(n=2,122)$ of the respondents were between the ages $19-39$, while $9.1 \%(n=213)$ were older than 40 years. The majority of the participants $(68.1 \%, \mathrm{n}=1,591)$ were currently attending, or graduated from a four-year college, followed by those currently attending, or graduated from a community college (12.1\%, $n=282)$, graduate school $(11.3 \%, n=263)$, and participants with school graduation or lower $(8.5 \%, \mathrm{n}=199)$. The greatest number of participants had an annual household income higher than 50

Table 2. SPR of poor self-rated health' between LGB population (2016) and the general population $(2013-2015)^{2}$ in Korea $(N=2,327)$

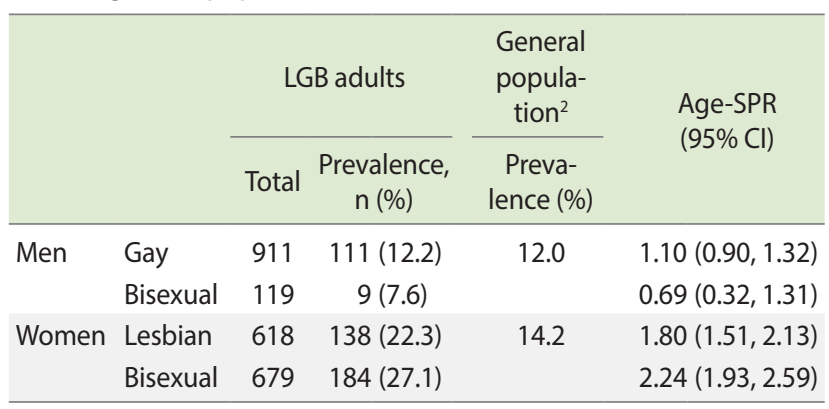

LGB, lesbian, gay, and bisexual; SPR, standardized prevalence ratio; $\mathrm{Cl}$, confidence interval.

${ }^{1}$ Responses of 'poor' and 'very poor' were categorized as negative selfrated health.

${ }^{2}$ Korea National Health and Nutrition Examination Survey VI (men: 19-60 yr; women: 19-50 yr). million Korean won $(22.2 \%, \mathrm{n}=516)$. In terms of employment status, $33.5 \%(n=777)$ of the respondents were currently students, followed by regular full-time workers $(25.4 \%, n=590)$, non-regular workers including fixed-term, hourly, contract, and special employment $(24.4 \%, \mathrm{n}=566)$, unemployed $(11.2 \%, \mathrm{n}=259)$, selfemployed or employer $(4.6 \%, \mathrm{n}=106)$, and non-paid family worker $(1.0 \%, \mathrm{n}=24)$. The greatest number of participants lived in Seoul $(47.8 \%, \mathrm{n}=1,113)$, followed by other metropolitan cities $(19.5 \%, \mathrm{n}=453)$, and other regions $(32.7 \%, \mathrm{n}=762)$.

\section{Comparison of the health status of Korean adult lesbian, gay, and bisexual and general populations}

Table 2 shows that $12.2 \%(n=111)$ of gay men, $7.6 \%(n=9)$ of bisexual men, $22.3 \%(n=138)$ of lesbians, and $27.1 \%(n=184)$ of bisexual women rated their health to be "poor" or "very poor."

In order to compare the prevalence of poor self-rated health in the Korean LGB adults with that in the general population, SPRs were calculated using data from 4,546 men (age, 19-60 years) and 4,432 women (age, 19-50 years) who participated in the KNHANES VI (2013-2015) as a general population. When compared to women in the general population, lesbians (SPR, 1.80; 95\% CI, 1.51 to 2.13 ) and bisexual women (SPR, 2.24; $95 \%$ CI, 1.93 to 2.59 ) reported poor self-rated health 1.80 times and 2.24 times more frequently, respectively. However, there were no statistically significant differences in the self-rated health between gay and bisexual men and men in the general population (Table 2).

SPRs of musculoskeletal pains over the past 12 months were calculated using data from 20,075 economically active men and 14,066 economically active women who participated in the 4th KWCS (2014) as a general population. The prevalence of back pain, upper limbs pain, and lower limbs pain was statistically significantly higher among LGB adults compared to the general population. For example, the prevalence of back pain was 2.85-3.40 times higher among gay men (SPR, 2.85; 95\% CI, 2.48 to 3.25 )

Table 3. SPR of musculoskeletal pain between LGB population (2016) and the general population (2014) ${ }^{1}$ in Korea

\begin{tabular}{|c|c|c|c|c|c|c|}
\hline & & & \multicolumn{2}{|c|}{ LGB adults } & \multirow{2}{*}{$\begin{array}{c}\text { General population }{ }^{1} \\
\text { Prevalence }(\%)\end{array}$} & \multirow{2}{*}{ Age-SPR $(95 \% \mathrm{Cl})$} \\
\hline & & & Total & Prevalence, n (\%) & & \\
\hline \multirow[t]{4}{*}{ Back pain $(n=2,322)$} & Men & Gay & 907 & $214(23.6)$ & 12.9 & $2.85(2.48,3.25)$ \\
\hline & & Bisexual & 120 & $30(25.0)$ & & $3.40(2.29,4.85)$ \\
\hline & Women & Lesbian & 617 & $237(38.4)$ & 14.7 & $3.88(3.41,4.41)$ \\
\hline & & Bisexual & 678 & $327(48.2)$ & & $5.39(4.83,6.01)$ \\
\hline \multirow{4}{*}{$\begin{array}{l}\text { Pain in the upper limbs } \\
\qquad(n=2,325)\end{array}$} & Men & Gay & 911 & $475(52.1)$ & 32.0 & $2.27(2.07,2.49)$ \\
\hline & & Bisexual & 119 & $71(59.7)$ & & $2.88(2.25,3.63)$ \\
\hline & Women & Lesbian & 617 & $471(76.3)$ & 34.4 & $3.08(2.81,3.37)$ \\
\hline & & Bisexual & 678 & $532(78.5)$ & & $3.42(3.14,3.73)$ \\
\hline \multirow{4}{*}{$\begin{array}{l}\text { Pain in the lower limbs } \\
(n=2,324)\end{array}$} & Men & Gay & 909 & $283(31.1)$ & 19.3 & $2.30(2.04,2.58)$ \\
\hline & & Bisexual & 121 & $46(38.0)$ & & $2.97(2.18,3.97)$ \\
\hline & Women & Lesbian & 618 & 305 (49.4) & 22.3 & $3.26(2.91,3.65)$ \\
\hline & & Bisexual & 676 & $372(55.0)$ & & $3.91(3.52,4.33)$ \\
\hline
\end{tabular}

SPR, standardized prevalence ratio; Cl, confidence interval; LGB, lesbian, gay, and bisexual.

14 th Korean Working Conditions Survey (men: 19-60 yr; women: 19-50 yr). 
and bisexual men (SPR, 3.40; 95\% CI, 2.29 to 4.85). Further, the prevalence of back pain was 3.88-5.39 times higher among lesbians (SPR, 3.88; 95\% CI, 3.41 to 4.41 ) and bisexual women (SPR, $5.39 ; 95 \%$ CI, 4.83 to 6.01 ) (Table 3 ).

Table 4 shows that $33.9 \%(n=305)$ of gay men, $36.4 \%(n=43)$ of bisexual men, $47.2 \%(n=288)$ of lesbians, and 59.2\% $(n=398)$ of bisexual women experienced depressive symptoms.

SPRs for depressive symptoms were calculated using data from 3,308 men and 2,705 women who participated in the 10th KWPS (2015). Compared to the general population, the prevalence of depressive symptoms was 7.13-7.16 times higher among gay men (SPR, 7.13; 95\% CI, 6.36 to 7.98) and bisexual men (SPR, 7.16; 95\% CI, 5.18 to 9.65), and 5.08-6.12 times higher among lesbians (SPR, 5.08; 95\% CI, 4.51 to 5.70) and bisexual women (SPR, 6.12; 95\% CI, 5.54 to 6.76 ) (Table 4).

To the question "Have you ever had a serious thought about dying by suicide in the past 12 months?", $25.7 \%(n=233)$ of gay men, $28.7 \%(n=35)$ of bisexual men, $34.6 \%(n=214)$ of lesbians, and $47.6 \%(\mathrm{n}=323)$ of bisexual women answered "yes." To the question "Have you ever attempted to die by suicide in the past 12 months?", $3.6 \%(n=33)$ gay men, $4.2 \%(n=5)$ of bisexual men, $4.6 \%(n=28)$ of lesbians, and $6.3 \%(n=43)$ of bisexual women answered "yes."

Compared to the general population who participated in the KNHANES VI (2013-2015), the prevalence of suicidal ideation over the past 12 months was 9.09-10.93 times higher among gay and bisexual men (gay men SPR, 9.09; 95\% CI, 7.96 to 10.34, bisexual men SPR, 10.93; 95\% CI, 7.61 to 15.20 ), 6.25-8.08 times higher among lesbians and bisexual women (SPR for lesbians, 6.25; 95\% CI, 5.44 to 7.14, SPR for bisexual women, 8.08; 95\% CI, 7.22 to 9.01 ) (Table 5). The suicide attempts were about 26-38 times more frequent in gay and bisexual men (SPR for gay men, 25.59; $95 \%$ CI, 17.61 to 35.94 , SPR for bisexual men, 37.65; $95 \%$ CI, 12.23 to 87.86), and 7-10 times more frequent in lesbians and bisexual women (SPR for lesbian, 7.11; 95\% CI, 4.72 to 10.27, SPR for bisexual women, 10.09 ; $95 \% \mathrm{CI}, 7.30$ to 13.60 ) than in the general population (Table 5).

In order to compare the prevalence of smoking and hazardous drinking of the Korean LGB adults with that of the general population, SPRs were calculated using data from 24,083 economically active men and 14,349 economically active women who participated in the 3rd KWCS (2011).

A total of $39.8 \%(n=361)$ of gay men, $27.9 \%(n=34)$ of bisexual men, $39.8 \%(n=246)$ of lesbians, and $31.9 \%(n=215)$ of bisexual women reported to be current smokers. When compared to the general population, the prevalence of smoking was about 6-7 times higher among lesbians and bisexual women (SPR for lesbians, 7.06; 95\% CI, 6.21 to 8.00 , SPR for bisexual women, 5.64; $95 \%$ CI, 4.91 to 6.45 ) (Table 6). In contrast, the prevalence of smoking among gay and bisexual men are statistically significant-

Table 4. SPR of depressive symptoms ${ }^{1}$ between LGB population (2016) and the general population $(2015)^{2}$ in $\mathrm{Korea}(\mathrm{N}=2,299)$

\begin{tabular}{|c|c|c|c|c|c|}
\hline & & \multicolumn{2}{|c|}{ LGB adults } & \multirow{2}{*}{$\begin{array}{c}\text { General population }{ }^{2} \\
\text { Prevalence (\%) }\end{array}$} & \multirow{2}{*}{ Age-SPR $(95 \% \mathrm{Cl})$} \\
\hline & & Total & Prevalence, n (\%) & & \\
\hline \multirow[t]{2}{*}{ Men } & Gay & 899 & $305(33.9)$ & 5.6 & $7.13(6.36,7.98)$ \\
\hline & Bisexual & 118 & $43(36.4)$ & & $7.16(5.18,9.65)$ \\
\hline \multirow[t]{2}{*}{ Women } & Lesbian & 610 & $288(47.2)$ & 7.3 & $5.08(4.51,5.70)$ \\
\hline & Bisexual & 672 & $398(59.2)$ & & $6.12(5.54,6.76)$ \\
\hline
\end{tabular}

SPR, standardized prevalence ratio; LGB, lesbian, gay, and bisexual; $\mathrm{Cl}$, confidence interval.

'Depressive symptoms were measured using the Center for Epidemiologic Studies-Depression Scale-D 11.

${ }^{2} 10$ th Korea Welfare Panel Study (men: 19-60 yr; women: 19-50 yr).

Table 5. SPR of suicidal ideation and suicide attempts over the past 12 months between LGB population (2016) and the general population (2013-2015) ${ }^{1}$ in Korea

\begin{tabular}{|c|c|c|c|c|c|c|}
\hline & & & \multicolumn{2}{|c|}{ LGB adults } & \multirow{2}{*}{$\begin{array}{c}\text { General population }{ }^{1} \\
\text { Prevalence (\%) }\end{array}$} & \multirow{2}{*}{ Age-SPR $(95 \% \mathrm{Cl})$} \\
\hline & & & Total & Prevalence, n (\%) & & \\
\hline \multirow{4}{*}{$\begin{array}{l}\text { Suicidal ideation } \\
\qquad(\mathrm{n}=2,325)\end{array}$} & Men & Gay & 907 & $233(25.7)$ & 3.5 & $9.09(7.96,10.34)$ \\
\hline & & Bisexual & 122 & $35(28.7)$ & & $10.93(7.61,15.20)$ \\
\hline & Women & Lesbian & 618 & $214(34.6)$ & 5.0 & $6.25(5.44,7.14)$ \\
\hline & & Bisexual & 678 & $323(47.6)$ & & $8.08(7.22,9.01)$ \\
\hline \multirow{4}{*}{$\begin{array}{l}\text { Suicide attempts } \\
(n=2,322)\end{array}$} & Men & Gay & 908 & $33(3.6)$ & 0.3 & $25.59(17.61,35.94)$ \\
\hline & & Bisexual & 120 & $5(4.2)$ & & $37.65(12.23,87.86)$ \\
\hline & Women & Lesbian & 614 & $28(4.6)$ & 0.7 & $7.11(4.72,10.27)$ \\
\hline & & Bisexual & 680 & $43(6.3)$ & & $10.09(7.30,13.60)$ \\
\hline
\end{tabular}

SPR, standardized prevalence ratio; LGB, lesbian, gay, and bisexual; $\mathrm{Cl}$, confidence interval.

${ }^{1}$ Korea National Health and Nutrition Examination Survey VI (men: 19-60 yr; women: 19-50 yr). 
Table 6. SPR of smoking and hazardous drinking ${ }^{1}$ between LGB population (2016) and the general population (2011) ${ }^{2}$ in Korea

\begin{tabular}{|c|c|c|c|c|c|c|}
\hline & & & \multicolumn{2}{|c|}{ LGB adults } & \multirow{2}{*}{$\begin{array}{c}\text { General population }{ }^{2} \\
\text { Prevalence (\%) }\end{array}$} & \multirow{2}{*}{ Age-SPR $(95 \% \mathrm{Cl})$} \\
\hline & & & Total & Prevalence, n (\%) & & \\
\hline \multirow[t]{4}{*}{ Smoking $(n=2,321)$} & Men & Gay & 907 & $361(39.8)$ & 55.3 & $0.73(0.65,0.81)$ \\
\hline & & Bisexual & 122 & $34(27.9)$ & & $0.51(0.36,0.72)$ \\
\hline & Women & Lesbian & 618 & $246(39.8)$ & 5.7 & $7.06(6.21,8.00)$ \\
\hline & & Bisexual & 674 & $215(31.9)$ & & $5.64(4.91,6.45)$ \\
\hline \multirow{4}{*}{$\begin{array}{l}\text { Hazardous drinking }{ }^{1} \\
(\mathrm{n}=2,089)\end{array}$} & Men & Gay & 823 & $180(21.9)$ & 21.6 & $1.17(1.00,1.35)$ \\
\hline & & Bisexual & 109 & $22(20.2)$ & & $1.12(0.70,1.70)$ \\
\hline & Women & Lesbian & 553 & 99 (17.9) & 7.3 & $2.18(1.77,2.66)$ \\
\hline & & Bisexual & 604 & $76(12.6)$ & & $1.45(1.15,1.82)$ \\
\hline
\end{tabular}

SPR, standardized prevalence ratio; LGB, lesbian, gay, and bisexual; Cl, confidence interval.

${ }^{1}$ Following the Korean national guideline of the hazardous drinking, people who drink more than 7 drinks (for men) and 5 drinks (for women) per occasion and more than two time per week were classified as hazardous drinkers.

23rd Korean Working Conditions Survey (men: 19-60 yr; women: 19-50 yr).

ly lower than general population (SPR for gay men, 0.73 ; $95 \% \mathrm{CI}$, 0.65 to 0.81 , SPR for bisexual men, $0.51 ; 95 \% \mathrm{CI}, 0.36$ to 0.72 ).

The prevalence of hazardous drinking was found to be $21.9 \%$ $(n=180)$ for gay men, $20.2 \%(n=22)$ for bisexual men, $17.9 \%$ $(\mathrm{n}=99)$ for lesbians, and $12.6 \%(\mathrm{n}=76)$ for bisexual women. When compared to the general population, prevalence of hazardous drinking was 2.18 times and 1.45 times higher among lesbians and bisexual women, respectively (SPR for lesbians, 2.18; 95\% CI, 1.77 to 2.66 , SPR for bisexual women, $1.45 ; 95 \%$ CI, 1.15 to 1.82 ), and 1.17 times higher among gay men (SPR, 1.17; 95\% CI, 1.00 to 1.35) (Table 6).

\section{DISCUSSION}

The present study showed that the overall health of the LGB adults in Korea is poorer than that of the general population. Compared to the general population, there was a higher prevalence of depressive symptoms, suicidal ideation and attempts, and musculoskeletal pains among Korean LGB adults. For women, the prevalence of reporting poor self-rated health and smoking was higher in the LGB population, and the prevalence of hazardous drinking was higher in the LGB population, with the exception of bisexual men, than in the general population. These findings are consistent with previous studies on health disparities of the LGB population [1-11].

The results about suicidal ideation and attempts in the Korean LGB adults particularly deserve attention. Our findings revealed that the prevalence of suicidal ideation among LGB adults was about 6.25 (lesbians) to 10.93 (bisexual men) times higher, and the prevalence of suicide attempts over the past 12 months was about 7.11 (lesbians) to 37.65 (bisexual men) times higher than in the general population. Korea has the highest suicide rate among Organization for Economic Cooperation and Development countries (29.1 suicides per 100,000 population) as of 2013 [22] and suicide is the main leading cause of death in Korean adults in their 20s-50s [23]. Considering these facts, our finding about suicidality of Korean LGB adults is very alarming.

To explain the health disparities of Korean LGB adults observed in this study, the minority stress processes in LGB population may be a useful framework [24]. Meyer [24] termed the stress experienced by sexual minorities in society due to their minority status as "minority stress" and theorized the process through which minority stress influences the mental health of sexual minorities. According to this model, all humans experience stressors in their daily lives but sexual minorities experience additional stressors leading to adverse health outcomes such as experiences of prejudice events, internalized homophobia, and expectations of rejection [24-29].

The minority stress model suggests that the hostile social environment for sexual minorities in Korea may be a key factor that exacerbates the health of sexual minorities. According to the Social Integration Survey in 2016, 55.8\% of the respondents stated that they "do not accept" homosexuals [30]. Compared to the social acceptance toward other minority groups (North Korean defectors $12.1 \%$, foreign immigrants or laborers $7.1 \%$, people with disabilities $1.3 \%$ ), the social acceptance for homosexuals is very low in Korea [30]. Furthermore, anti-lesbian, gay, bisexual, and transgender (LGBT) movement has been rapidly organized in Korea since the mid-2000s, and hate expressions against LGBT people have emerged as an important social problem [31-33]. In such social environment, various negative social experiences that sexual minorities face may worsen their health. Korean studies reported associations between social stigma and low life satisfaction in LGB adults [34] and between the experience of anti-gay violence and suicide risk in gay adolescents [35]. Further studies are needed to understand to what extent negative social experiences within the hostile environment of Korea explain for health disparities of LGB adults found in this study.

Another notable finding of this study is the differences in health status within the LGB population. Although the SPRs for mental health and physical symptoms against the general population were high in all the sexual minority groups, there were differences in 
self-rated health and health-related behaviors within the groups. The prevalence of poor self-rated health was higher in lesbians and bisexual women than in the general population, but no statistical difference was found among men. While lesbians and bisexual women showed a significantly higher prevalence of smoking than did the general population, gay and bisexual men showed a significantly lower prevalence of smoking than did the general population. Furthermore, SPRs for hazardous drinking was the highest in lesbians, followed by bisexual women and gay men, while there was no significant difference between bisexual men and the general population.

Previous studies also showed differences in health status among LGB population, but the findings were not consistent [1-5]. Further studies are needed to identify the factors and mechanisms behind health disparities within sexual minorities. More detailed examination on socio-demographic variables, such as gender, age, and socioeconomic status, is needed from an intersectional perspective before simply adjusting for them in the analysis. Additionally, more studies are needed to explore the health of lesbians and bisexual women. Both of them are relatively neglected populations in Korea LGBT health researches.

The present study has the following limitations. First, we cannot exclude the possibility that SPRs might be overestimated due to the difference in survey methods between our survey and the national health surveys used for the general population. Although the same questionnaires were used, we conducted an online survey while all the national-level health surveys were administered through face-to-face interview. Given the fact that sensitive questions, such as suicidal ideation and attempts, are more likely to be underreported in an in-person interview, it is difficult to completely exclude the possibility of overestimation of SPRs for suicidal behaviors. Second, there may be the possibility of potential under estimation of SPRs for musculoskeletal pains and healthrelated behaviors due to the difference in survey participants. Among our survey participants 33.5\% were students, while participants of the KWCS used as a comparison group were limited to economically active population. Considering that the prevalence of musculoskeletal pains and health-related behaviors is generally higher in working populations, there is a possibility that the SPRs for those were underestimated. Third, the comparison group may have LGB individuals because those nationally representative surveys did not include sexual orientation measure in their questionnaires. Hence, it should be noted that the findings of this study were only a comparison of the health status of the Korean LGB adults with the general population, and not a comparison between LGB adults and their heterosexual counterparts.

Finally, the limitation of our study is that the representativeness of the sample cannot be ensured, as we used convenience sampling. The majority of participants were in their 20s-30s (90.9\%) with high levels of education and income. It may be attributable to the fact that survey promotion and recruitment relied heavily on online and offline networks of sexual minority organizations and communities, as low-income and low-educated older LGB individuals may have lower access to such networks. In that case, there is a possibility that the SPRs in this study might be underestimated.

To address the limitations of this study and to gain a more systematic understanding of the health disparities of the Korean LGB population, nationally representative surveys should include sexual orientation in their questionnaires. A growing number of health surveys in North America and Europe include sexual orientation as a demographic variable, based on which many studies are conducted to investigate health disparities of sexual minorities $[1-3,6,7,9,10,36,37]$. The Korea Youth Risk Behavior Web-based Survey is the only national-level health survey in Korea measuring sexual orientation by asking respondents to indicate the gender of the person with whom they had a sexual intercourse. These data enabled studies to compare the health status of LGB adolescents with heterosexual counterparts [13-15]. To facilitate LGBT health studies in Korea, sexual orientation needs to be included as a demographic variable in national-level health surveys, such as the KNHANES and Work Environment Survey.

The present study aimed to investigate the magnitude of health disparities faced by the Korean LGB adults using the largest Korean dataset on LGB individuals. Future studies should take a step further to identify social factors that might worsen or improve their health. Furthermore, policy interventions should be implemented to improve the health and quality of life of sexual minorities in Korea.

\section{ACKNOWLEDGEMENTS}

This work was partially supported by the Korean Gay Men's Human Rights Group Chingusai and the Beautiful Foundation. Many thanks to the members of the LGBTAIQP Suicide Prevention Project Connectyourhearts of Chingusai for their assistance in survey development and promotion.

\section{CONFLICT OF INTEREST}

The authors have no conflicts of interest to declare for this study.

\section{SUPPLEMENTARY MATERIAL}

Supplementary material (Korean version) is available at http:// www.e-epih.org/.

\section{ORCID}

Horim Yi: https://orcid.org/0000-0003-1118-272X; Hyemin Lee: https://orcid.org/0000-0001-9257-6434; Jooyoung Park: https://orcid.org/0000-0001-9765-2707; Bokyoung Choi: https://orcid.org/ 0000-0002-9842-9395; Seung-Sup Kim: https://orcid.org/00000003-1830-0282 


\section{REFERENCES}

1. Bränström R, Hatzenbuehler ML, Pachankis JE. Sexual orientation disparities in physical health: age and gender effects in a population-based study. Soc Psychiatry Psychiatr Epidemiol 2016;51: 289-301.

2. Conron KJ, Mimiaga MJ, Landers SJ. A population-based study of sexual orientation identity and gender differences in adult health. Am J Public Health 2010;100:1953-1960.

3. Sandfort TG, Bakker F, Schellevis FG, Vanwesenbeeck I. Sexual orientation and mental and physical health status: findings from a Dutch population survey. Am J Public Health 2006;96:11191125.

4. Sandfort TG, de Graaf R, Bijl RV, Schnabel P. Same-sex sexual behavior and psychiatric disorders: findings from the Netherlands Mental Health Survey and Incidence Study (NEMESIS). Arch Gen Psychiatry 2001;58:85-91.

5. Dilley JA, Simmons KW, Boysun MJ, Pizacani BA, Stark MJ. Demonstrating the importance and feasibility of including sexual orientation in public health surveys: health disparities in the Pacific Northwest. Am J Public Health 2010;100:460-467.

6. Gilman SE, Cochran SD, Mays VM, Hughes M, Ostrow D, Kessler RC. Risk of psychiatric disorders among individuals reporting same-sex sexual partners in the National Comorbidity Survey. Am J Public Health 2001;91:933-939.

7. Diamant AL, Wold C. Sexual orientation and variation in physical and mental health status among women. J Womens Health (Larchmt) 2003;12:41-49.

8. Gruskin EP, Gordon N. Gay/lesbian sexual orientation increases risk for cigarette smoking and heavy drinking among members of a large Northern California health plan. BMC Public Health 2006;6:241.

9. Steele LS, Ross LE, Dobinson C, Veldhuizen S, Tinmouth JM. Women's sexual orientation and health: results from a Canadian population-based survey. Women Health 2009;49:353-367.

10. Cochran SD, Mays VM. Relation between psychiatric syndromes and behaviorally defined sexual orientation in a sample of the US population. Am J Epidemiol 2000;151:516-523.

11. Cochran SD, Mays VM, Sullivan JG. Prevalence of mental disorders, psychological distress, and mental health services use among lesbian, gay, and bisexual adults in the United States. J Consult Clin Psychol 2003;71:53-61.

12. Lee MH, Park JY, Kim SS. LGBTQI health research in South Korea: a systematic review. Health Soc Sci 2014;36:43-76 (Korean).

13. Yoon JH, So WY. Differences in lifestyles including physical activity according to sexual orientation among Korean adolescents. Iran J Public Health 2013;42:1347-1353.

14. Lee DY, Kim SH, Woo SY, Yoon BK, Choi D. Associations of healthrisk behaviors and health cognition with sexual orientation among adolescents in school: analysis of pooled data from Korean nationwide survey from 2008 to 2012. Medicine (Baltimore) 2016;95: e3746.

15. Kim GH, Ahn HS, Kim HJ. Type of sexual intercourse experience and suicidal ideation, plans, and attempts among youths: a crosssectional study in South Korea. BMC Public Health 2016;16:1229.

16. Jung M, Lee J, Kwon DS, Park BJ. Comparison of sexual risky factors of men who have sex with men and sex-buying men as groups vulnerable to sexually transmitted diseases. J Prev Med Public Health 2012;45:156-163.

17. Kong SU, Oh KS, No KS. The Comparison of the quality of life and mental health in homosexual men and heterosexual men. J Korean Neuropsychiatr Assoc 2002;41:930-941 (Korean).

18. Park KH. The comparison of psychopathology in homosexuality and gender identity disorder: based on candidates referred by army for medical certificate. Korean J Clin Psychol 2005;24:549-561 (Korean).

19. Jung M. Sexual behavior and condom use among gay men, female sex workers, and their customers: evidence from South Korea. PLoS One 2013;8:e66867.

20. Lee YS, Jeon CM, Kim SY, Ko BJ. Self esteem and sexual liberality of adolescent with gender identity problem or homosexual tendency. J Korean Acad Child Adolesc Psychiatry 2005;16:231-238 (Korean).

21. Organization for Economic Cooperation and Development. Tackling harmful alcohol use: economics and public health policy; 2015 [cited 2017 Dec 16]. Available from: http://iogt.org/wp-content/uploads/2015/03/OECD-report-2015.pdf.

22. Organization for Economic Cooperation and Development. OECD factbook 2015-2016: economic, environmental and social statistics [cited 2017 Dec 16]. Available from: http://dx.doi.org/10.1787/ factbook-2015-en.

23. Statistics Korea. Annual report on the cause of death statistics 2015; 2016 [cited 2017 Jul 5]. Available from: http://www.index. go.kr/potal/main/EachDtlPageDetail.do?idx_cd=1012 (Korean).

24. Meyer IH. Prejudice, social stress, and mental health in lesbian, gay, and bisexual populations: conceptual issues and research evidence. Psychol Bull 2003;129:674-697.

25. Kuyper L, Fokkema T. Minority stress and mental health among Dutch LGBs: examination of differences between sex and sexual orientation. J Couns Psychol 2011;58:222-233.

26. Frost DM, Lehavot K, Meyer IH. Minority stress and physical health among sexual minority individuals. J Behav Med 2015;38: 1-8.

27. Andersen JP, Zou C, Blosnich J. Multiple early victimization experiences as a pathway to explain physical health disparities among sexual minority and heterosexual individuals. Soc Sci Med 2015;133:111-119.

28. Lehavot K, Simoni JM. The impact of minority stress on mental health and substance use among sexual minority women. J Consult Clin Psychol 2011;79:159-170.

29. Roberts AL, Austin SB, Corliss HL, Vandermorris AK, Koenen KC. Pervasive trauma exposure among US sexual orientation minority adults and risk of posttraumatic stress disorder. Am J Public Health 2010;100:2433-2441.

30. Research Center on Social Cohesion. 2015 Korea social integration survey: final report. Seoul: Korea Institute of Public Admin- 
istration; 2017, p. 169-174. (Korean).

31. Yi H, Kim SS. Anti-LGBT movement in South Korea and the professionals on their side. Psychol Sex Rev 2016;7:83-85.

32. Lee NY, Baek JY. Politics of disgust: Korean conservative protestant discourses against homosexuality. J Womens Stud 2017;27: 67-108 (Korean).

33. Hong SS, Kim JH, Noh JS, Ryu MH, Lee SH, Lee JY, et al. A research on hate-speech in Korea and measures for regulation: final report. Seoul: National Human Rights Commission of Korea; 2016, p. 226-228 (Korean).

34. Kang BC. The effects of perceived social stigma on the life satisfaction of sexual minorities. Korean J Soc Welf Stud 2011;42:381-
417 (Korean).

35. Kang BC, Ha KH. A study on homosexual adolescents' sexual identity and suicidal risk. Korean J Youth Stud 2005;12:267-289 (Korean).

36. Wichstrøm L, Hegna K. Sexual orientation and suicide attempt: a longitudinal study of the general Norwegian adolescent population. J Abnorm Psychol 2003;112:144-151.

37. Ward BW, Dahlhamer JM, Galinsky AM, Joestl SS. Sexual orientation and health among US adults: National Health Interview Survey, 2013. Hyattsville: National Center for Health Statistics; 2014, p. 1-12. 
Appendix 1. SPR of 6 physical symptoms between LGB population (2016) and the general population (2014) ${ }^{1}$ in South Korea

\begin{tabular}{|c|c|c|c|c|c|c|}
\hline & & & \multicolumn{2}{|c|}{ LGB adults } & \multirow{2}{*}{$\begin{array}{c}\text { General population }{ }^{1} \\
\text { Prevalence (\%) }\end{array}$} & \multirow{2}{*}{ Age-SPR (95\% Cl) } \\
\hline & & & Total & Prevalence, n (\%) & & \\
\hline \multirow{4}{*}{$\begin{array}{l}\text { Hearing problems } \\
\qquad(\mathrm{n}=2,322)\end{array}$} & \multirow{2}{*}{ Men } & Gay & 907 & $78(8.6)$ & 1.8 & $7.41(5.86,9.25)$ \\
\hline & & Bisexual & 121 & $11(9.1)$ & & $7.96(3.97,14.24)$ \\
\hline & \multirow[t]{2}{*}{ Women } & Lesbian & 617 & $59(9.6)$ & 1.1 & $8.44(6.42,10.89)$ \\
\hline & & Bisexual & 677 & $63(9.3)$ & & $8.28(6.36,10.60)$ \\
\hline \multirow{4}{*}{$\begin{array}{l}\text { Skin problems } \\
(\mathrm{n}=2,325)\end{array}$} & \multirow[t]{2}{*}{ Men } & Gay & 907 & $316(34.8)$ & 2.2 & $17.32(15.46,19.33)$ \\
\hline & & Bisexual & 120 & $45(37.5)$ & & $17.56(12.81,23.50)$ \\
\hline & \multirow[t]{2}{*}{ Women } & Lesbian & 618 & $261(42.2)$ & 2.7 & $12.75(11.25,14.40)$ \\
\hline & & Bisexual & 680 & $333(49.0)$ & & $15.08(13.50,16.79)$ \\
\hline \multirow{4}{*}{$\begin{array}{l}\text { Headaches/eyestrain } \\
(n=2,327)\end{array}$} & \multirow[t]{2}{*}{ Men } & Gay & 909 & $627(69.0)$ & 20.1 & $4.56(4.21,4.93)$ \\
\hline & & Bisexual & 120 & $87(72.5)$ & & $5.32(4.26,6.56)$ \\
\hline & \multirow[t]{2}{*}{ Women } & Lesbian & 618 & $524(84.8)$ & 22.7 & $4.34(3.98,4.73)$ \\
\hline & & Bisexual & 680 & $604(88.8)$ & & $4.83(4.46,5.23)$ \\
\hline \multirow{4}{*}{$\begin{array}{l}\text { Stomach ache } \\
(n=2,321)\end{array}$} & \multirow[t]{2}{*}{ Men } & Gay & 907 & $280(30.9)$ & 1.4 & $23.78(21.08,26.74)$ \\
\hline & & Bisexual & 120 & $35(29.2)$ & & $22.78(15.87,31.68)$ \\
\hline & \multirow[t]{2}{*}{ Women } & Lesbian & 617 & $307(49.8)$ & 2.0 & $23.27(20.74,26.03)$ \\
\hline & & Bisexual & 677 & $408(60.3)$ & & $28.20(25.53,31.07)$ \\
\hline \multirow{4}{*}{$\begin{array}{l}\text { Respiratory difficulties } \\
\quad(n=2,324)\end{array}$} & \multirow[t]{2}{*}{ Men } & Gay & 908 & $77(8.5)$ & 0.7 & $17.09(13.49,21.36)$ \\
\hline & & Bisexual & 120 & $9(7.5)$ & & $15.16(6.93,28.77)$ \\
\hline & \multirow[t]{2}{*}{ Women } & Lesbian & 618 & $107(17.3)$ & 0.4 & $59.23(48.54,71.57)$ \\
\hline & & Bisexual & 678 & $131(19.3)$ & & $65.32(54.62,77.52)$ \\
\hline \multirow{4}{*}{$\begin{array}{l}\text { Overall fatigue } \\
(n=2,326)\end{array}$} & \multirow[t]{2}{*}{ Men } & Gay & 910 & $549(60.3)$ & 24.5 & $3.28(3.01,3.56)$ \\
\hline & & Bisexual & 121 & $74(61.2)$ & & $3.64(2.86,4.57)$ \\
\hline & \multirow[t]{2}{*}{ Women } & Lesbian & 618 & $461(74.6)$ & 23.6 & $4.24(3.87,4.65)$ \\
\hline & & Bisexual & 677 & $528(78.0)$ & & $4.87(4.47,5.31)$ \\
\hline
\end{tabular}

SPR, standardized prevalence ratio; LGB, lesbian, gay, and bisexual; $\mathrm{Cl}$, confidence interval.

${ }^{1} 4$ th Korean Working Conditions Survey (men: 19-60 yr; women: 19-50 yr). 